\title{
System Design and Implementation of Smart Dashboard for Electric Vehicles
}

\author{
Jia-Sheng Hu and Chien-Chu Yeh \\ Department of Greenergy, National University of Tainan, Tainan 700, Taiwan \\ Correspondence should be addressed to Jia-Sheng Hu; jogson@gmail.com
}

Received 15 September 2014; Accepted 12 December 2014

Academic Editor: Mo Li

Copyright (C) 2015 J.-S. Hu and C.-C. Yeh. This is an open access article distributed under the Creative Commons Attribution License, which permits unrestricted use, distribution, and reproduction in any medium, provided the original work is properly cited.

\begin{abstract}
Recently, the development of automobile focuses on the chassis structure and motion control. However, due to the concept of smart and safe vehicle, the integrated dashboard becomes a necessary issue. The proposed system can not only represent the conventional dashboard in a digital form but also endow the system with an intelligent guidance. The statuses such as speed, battery SOC, braking, mileage, and the activation of TCS and ABS can be seen and monitored in all driving scenarios. For example, the current modern electric vehicles face the danger of self-ignition problem when the over load problem is consisted. Basically, these severe conditions can be eliminated by a guard of smart interface. Consequently, under a proper design, the presented system can assist the driver to maintain the energy efficiency, steering stability, and so on. Then the operation procedure can be simplified and hence driver can concentrate more on steering.
\end{abstract}

\section{Introduction}

Usually, a good dashboard design facilitates safe steering experiences $[1,2]$. The whole platform should be user-friendly and functional rich. The electric vehicles (EVs) that share full states via electric signals. Hence a good dashboard reveals its importance in integration [3]. This paper investigates the system design and implementation of a vehicle's dashboard, which is endowed with quick response and highly integrated interface. This paper aims to make use of the advantages of electric vehicles to develop a smart dashboard system based on a hands-on electric vehicle "Corsa-EV" [4]. This prototype is a front-wheel drive in-wheel motor electric vehicle.

To implement a graphical dashboard, many platforms can be considered, such as Android, iOS, and Windows. In order to eliminate the complicated issues on development, this paper utilized software LabVIEW on Windows to develop the dashboard, which is used on a 10-inch touch panel. Due to this feature, the whole system is flexible and can be customized. Unlike the conventional dashboard, the presented one has digital graphic for a quicker comprehension and more reliable information representation. Due to the convenience of mobile communication, the proposed approach has a very good compatibility, which has a high potential to promote the concepts on smart EVs.

The presented system is an intelligent, multipurpose, and user-friendly information revealing system, which can not only display the vehicle's status such as speed, temperature, mileage, and functions but also show the current safety evaluations of steering. Regarding the vehicle's motion control status [5-8], technologies such as the tire's slip ratio, the activation of antilock braking system (ABS) and traction control system (TCS), and other advanced functions are also included. Additionally, for electrified transportation, the management of battery packs' state of charge (SOC) is also a crucial issue [9]. Therefore, such monitoring system is required due to the safety issue. Recently, the navigation and car rearview vision system are also popular functions. In this study, these mentioned functions will all be integrated into a dashboard on a touch panel.

This paper is structured as follows. Section 1 gives the introduction and motivation of the major investigation. Section 2 describes the presented system design and implementation of smart dashboard for electric vehicle. The battery 
monitor system, slip ratio monitor system, and power consumption management system are revealed in this section. Experimental illustrations for verification are also shown in this section. Finally, Section 3 offers some concluding remarks.

\section{The System Construction and Necessary Algorithms}

2.1. The Battery Model. For chemical batteries such as lithium-ion battery, the power efficiency decays to accompany the battery's lifetime. According to the research of Li et al. [10], lifetime of chemical batteries can be 10 times longer than the one without battery management system. Generally, the present capacity of a battery can be formulated as

$$
\operatorname{SOC}(t)=Q_{T}-\int_{t_{0}}^{t} i(\tau) d \tau,
$$

where $Q_{T}$ is the theoretical capacity of the battery. Usually, the practical capacity $Q_{p}$ of battery is always much lower compared to the theoretical capacity $Q_{T}$ due to practical limitations and battery protection. In general, the theoretical stored energy can be obtained as

$$
E_{T}=V_{\text {bat }} Q_{T} .
$$

However, the practical available energy is

$$
E_{p}=\int_{t_{0}}^{t_{\mathrm{cut}}} v i d t
$$

Battery is an expensive cost on electric vehicles. For seeking a long driving mileage especially, the cost of battery always dominated the price of the whole car. Therefore, the energy management is quite important due to the economy of power source. Obviously, under proper control and monitoring, the lifetime of battery can be guaranteed in a healthy charge and discharge scenarios. Consequently, the energy efficiency and safety can be ensured.

2.2. The Monitoring of Tire's Slip Ratio. To ensure a safe two-dimensional operation of a four-wheel vehicle, its longitudinal motion control is fundamental. As depicted in Figure 1, the dynamic differential equations for the longitudinal motion of the front-wheel drive electric vehicle can be described as

$$
\begin{gathered}
J_{w} \dot{\omega}=T-r F_{d}, \\
M \dot{V}=F_{d}-F_{\mathrm{dr}}, \\
V_{w}=r \omega, \\
F_{d}(\lambda)=\mu N,
\end{gathered}
$$

where the parameters' definitions are listed in Parameter List. Note that (4) stands for the wheel dynamics, (5) the vehicle dynamics, and (7) the tire tractive force. Basically, the nonlinear interrelationships between the slip ratio $\lambda$

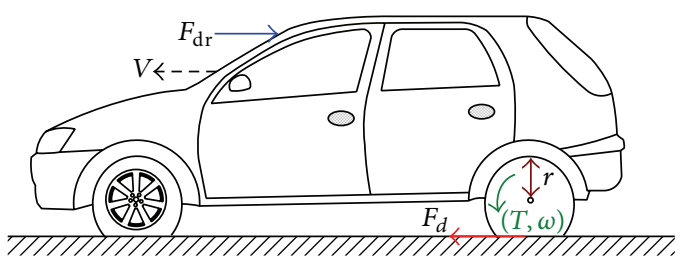

Figure 1: Dynamic longitudinal model of vehicle.

and friction coefficient $\mu$ formed by the tire's dynamics can be modeled by the widely adopted magic formula [11] as shown in Figure 2(a). Figure 2(a) shows the deterioration of longitudinal and lateral frication force with different slip ratios. The slip ratio $\lambda$ related to the wheel slip is defined as

$$
\lambda=\frac{V_{w}-V}{\max \left[V_{w}, V, \varepsilon\right]} \in[-1,1],
$$

where $\varepsilon$ is a small positive constant adopted to ensure a nonzero denominator. Here from Figure 2(a), obviously, as the slip ratio increases, the quick loss on lateral friction force [12] will cause the vehicle to enter an uncontrollable scenario. To ensure a safe steering situation, the vehicle's tractive force should be controlled in the effective traction zone as depicted in Figure 2(b). Maintaining the tractive force in the vehicle acceleration stage always falls under the traction control issues. Proper traction control offers an anti-skid mechanism to prevent the tire-saturation scenarios. Therefore, the safety of a steering vehicle can be further enhanced.

2.3. Power Consumption Management. Although the energy consumptions of electric vehicles cannot be counted by the rest fuel like the internal combustion engine vehicles, the electricity consumptions are still of reference. Usually, the computer controlled dashboard can predict the rest mileages from the stored electricity. In addition, the cost can be obtained by how much electricity has been used in the unit of $\mathrm{kWh}$. In this study, the electricity consumption in the proposed system is presented as

$$
C_{\mathrm{Ah}}=C_{\text {start }}-C_{\text {status }},
$$

where $C_{\mathrm{Ah}}$ is the rest battery capacity in the unit of Ah and $C_{\text {start }}$ and $C_{\text {status }}$ stand for the battery capacity in the beginning and measuring time, respectively. Consequently, the energy consumed by the system can be obtained as

$$
E_{\mathrm{kWh}}=V C_{\mathrm{Ah}},
$$

where $V$ is the rated battery voltage. By the obtained equation (10), the cost then can be set from the local electricity fair in the dashboard. For the convenience in proposed dashboard, the local electricity fair should be assigned by the operator.

2.4. System Construction. To develop the aforementioned dashboard for smart EVs, as mentioned in Section 1, Figure 3 shows the system schematic of the proposed system. The main functions and features of the proposed integrated dashboard 


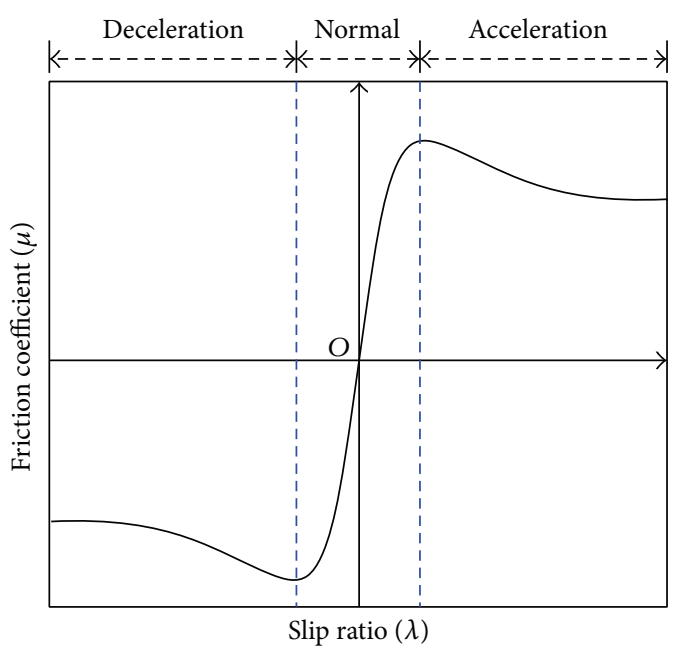

(a) Wheel traction with magic formula

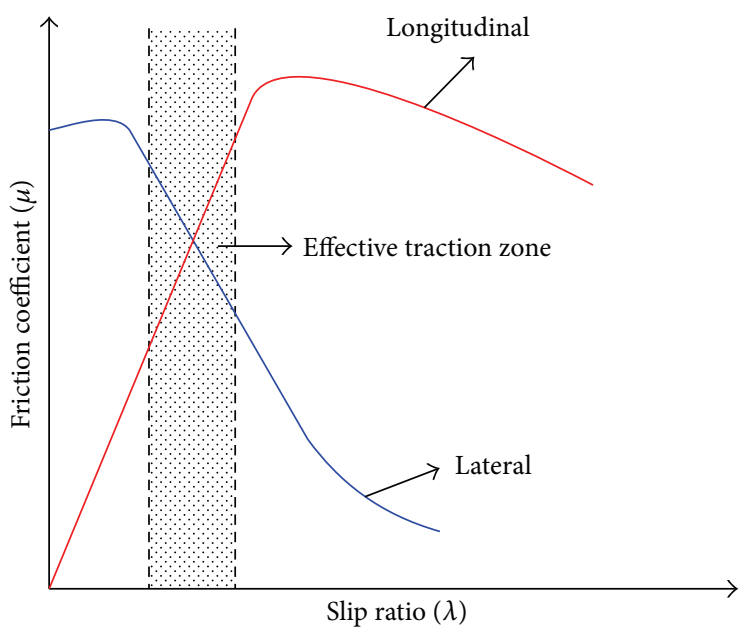

(b) Longitudinal and lateral friction force

FIGURE 2: Magic formula and effective traction force.

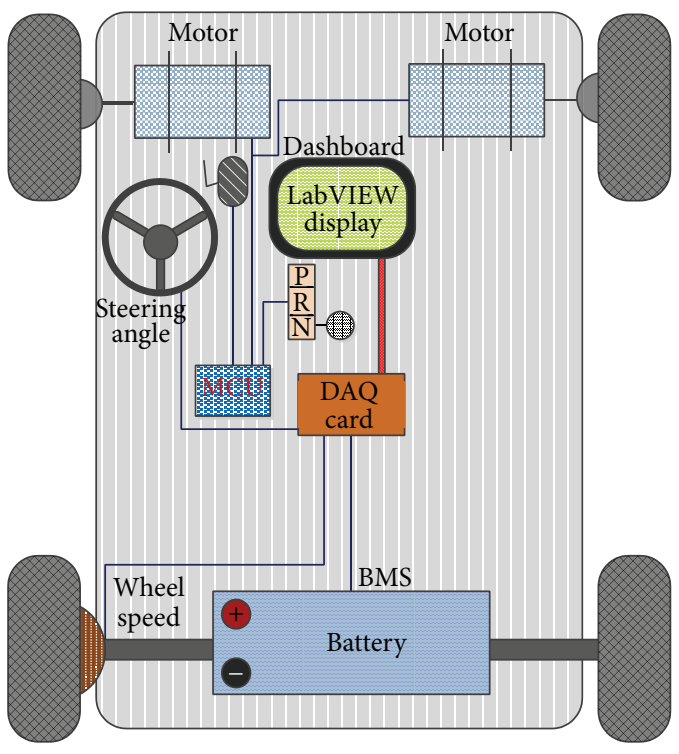

FIgURE 3: The schematic system.

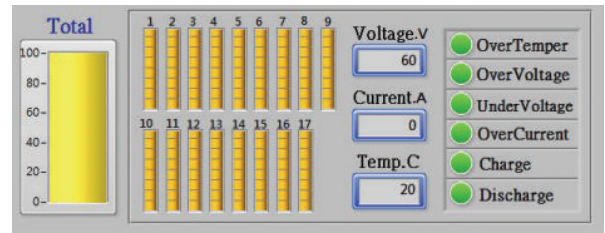

FIgURE 4: The status of all battery packs.

are summarized as follows. The status of battery management system (BMS) can be inspected in Figure 4, which is crucial to the energy management and safety. In this diagrammatic display, the battery's state of charge, voltage, current, and temperature all can be inspected. Figure 5 shows the setup of
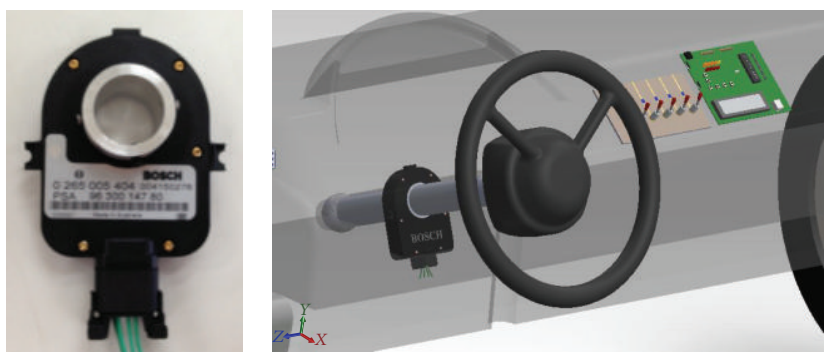

FIgURE 5: The turning angle sensor.
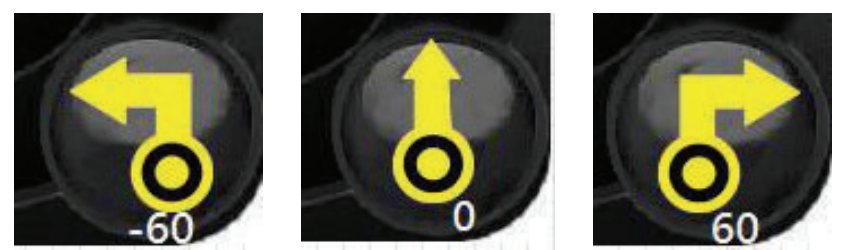

FIgURE 6: The display of turning status.

steering angle sensor. Figures 6 and 7 illustrate the display of steering angle and vehicle speed, respectively. The tire slip ratio is displayed in Figure 8. For safety consideration, if the slip ratio is higher than $40 \%$, the green light will be turned into red for an alarm. Figure 9 shows the setup of rearview camera, which is based on a webcam of the Logitech C170. When the operator initiates a reverse command, Figure 10 shows that the rearview camera will be activated simultaneously for steering assistance. Figure 11 illustrates the main display of proposed dashboard where Figure 12 shows its function indexes. When the user pushes the relevant icon, the subscreen will be opened. For instance, Figure 13 reveals the interior status of the whole battery. Figure 14 shows the fault diagnosis function of the system. The presented system can be 


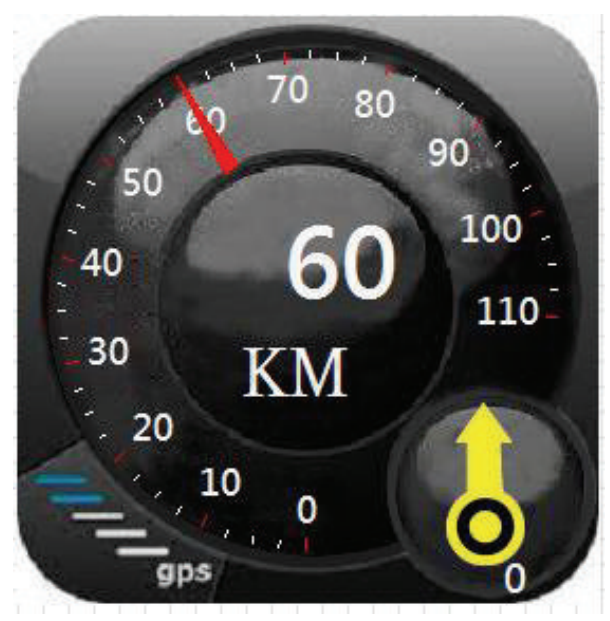

Figure 7: The vehicle speed meter.
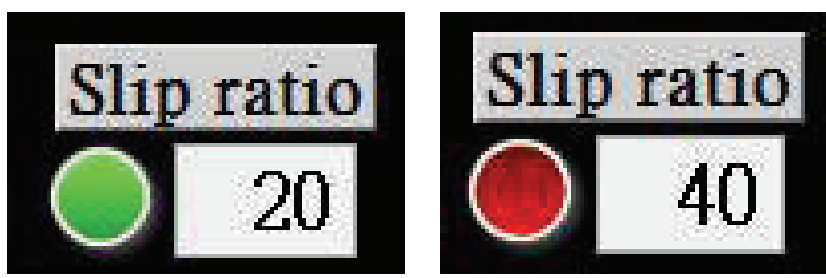

FIGURE 8: The tire's slip ratio.

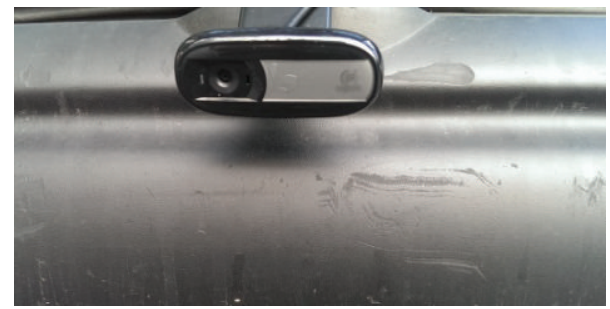

FIGURE 9: The rearview camera.

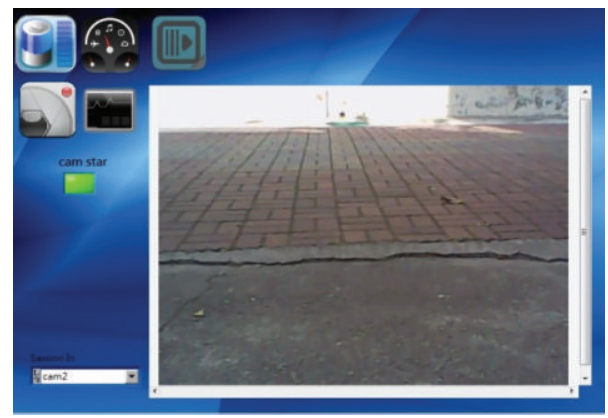

FIGURE 10: The rearview of a reversing.

split into several modules. From the status lights on Figure 14, the operator can check the potential malfunctions easily.

Note that the main contribution of this paper is not only the monitoring of system states but also the safety. In addition, the safety related information is presented in a graphical way for an easy and quick comprehension. Unlike

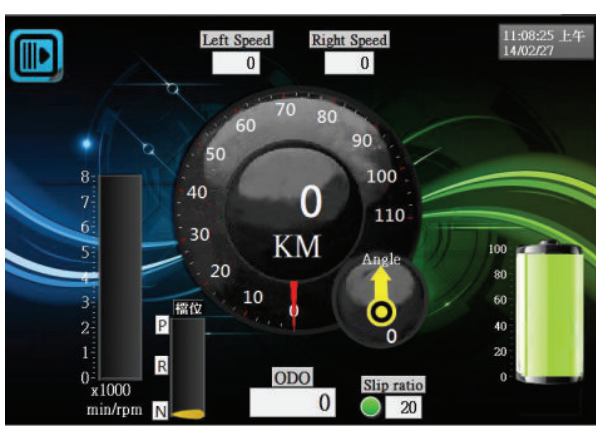

FIGURE 11: The main dashboard view.

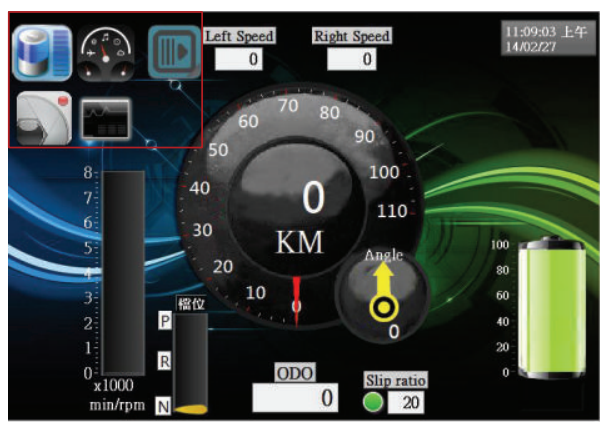

FIGURE 12: Function indexes.

the commercial dashboard, the presented smart system can carry out customization. Hence the system functions can be rich; however, the display can be clear and compact. The presented approach endows the dash board with a more flexible solution to enhance the driving experiences. Additionally, we know that the LabVIEW system is a bit expensive. However, it is stable and reliable. Consequently, we choose it as the platform of our smart dashboard. Basically, the presented approach can be exported to different platform such as the Microsoft or Android. Hence, readers can employ the proposed scheme to build similar systems on different platforms.

Figure 15 shows the process flowchart of the presented system. As can be seen in this figure, the smart dashboard plays an important role to assist the driver for a safe and easy steering. After all the subsystem functions are ready, the presented dashboard can be equipped on the real electric vehicle. Figure 16 shows the practical setup of the proposed smart dashboard on our prototype electric vehicle: Corsa-EV. The system works well in practice and can be considered as an alternative display platform for future electric vehicles.

\section{Conclusion}

In this paper, an integrated dashboard for smart electric vehicles has been constructed. The proposed system can not only replace the conventional dashboard in a digital form but also endow the driving system with an intelligent guidance. Statuses such as speed, battery SOC, braking, mileage, temperature, and the activation of TCS and ABS can be seen and inspected in all driving scenarios. Additionally, 


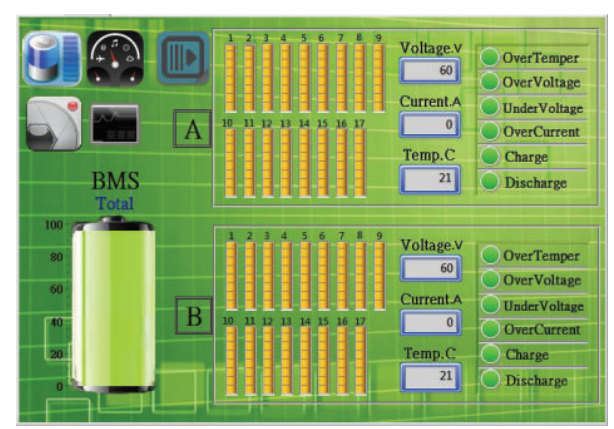

FIGURE 13: The interior battery status.

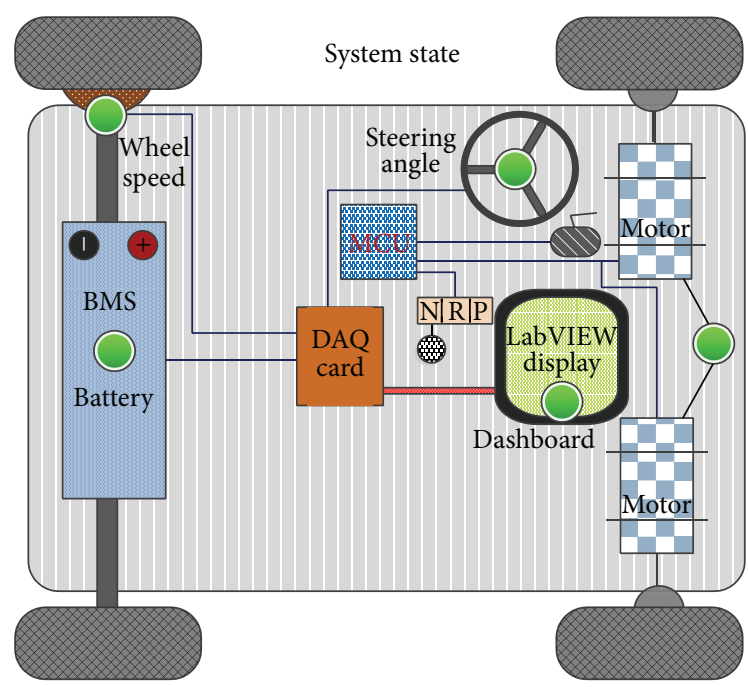

FIgURE 14: The schematic of fault diagnosis.

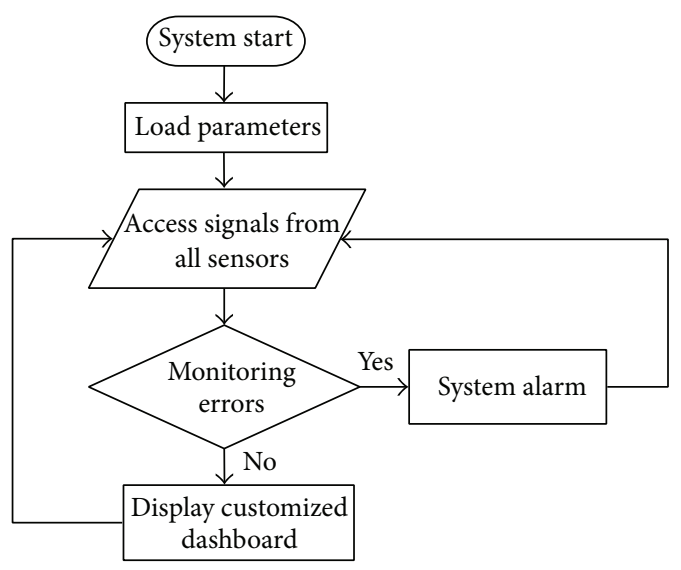

FIGURE 15: The process flowchart.

this system can not only reveal the steering information but also reveal the energy saving management. By applying such information into the known energy formulation, the energy consumption can be predicted and controlled. Consequently, the contribution of the proposed system is not only focused on the information display and monitoring but also focused on an energy consultant. For example, the severe conditions

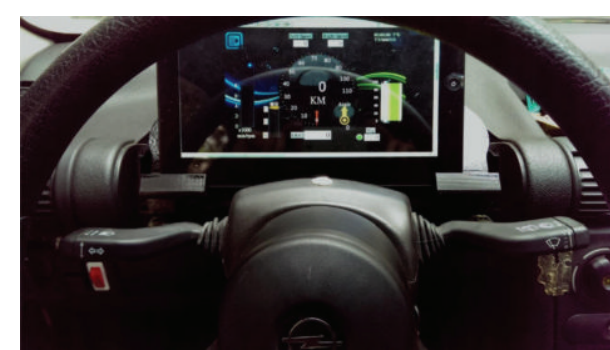

FIgURE 16: The real setup on Corsa-EV.

such as battery short circuit can be eliminated under the protection of proposed interface. The battery's lifetime and system's power economy have confirmed an improvement under the proposed energy management. These evaluations have demonstrated their effectiveness and potential feasibility. Moreover, the presented system can facilitate the driver to maintain the steering safety and stability in an easier way. Then the operation procedure can be simplified and hence driver can concentrate more on steering.

\section{Parameters List}

$J_{w}$ : Wheel inertia (motor included)

$V_{w}$ : Wheel circumferential velocity

$\omega$ : Wheel rotation

$T:$ Driving torque

$r$ : Wheel radius

$F_{d}:$ Friction force (driving force)

$M$ : Vehicle mass

$N$ : Vehicle weight

$V$ : Chassis velocity (vehicle velocity)

$F_{\mathrm{dr}}$ : Driving resistance

$\lambda:$ Slip ratio

$\mu$ : Friction coefficient.

\section{Conflict of Interests}

The authors declare that there is no conflict of interests regarding the publication of this paper.

\section{Acknowledgment}

This work was supported by Ministry of Science and Technology (MOST) of Taiwan, under Project MOST 102-2221-E024-014.

\section{References}

[1] R. K. Jurgen, "Automotive electronics: all-electronic dashboards coming: CRT, liquid crystal, and electroluminescent displays show promise for large-area, multifunction driver information systems in future cars," IEEE Spectrum, vol. 18, no. 6, pp. 34-37, 1981.

[2] B. Akin, S. Choi, and H. A. Toliyat, "DSP applications in electric and hybrid electric vehicles," IEEE Signal Processing Magazine, vol. 29, no. 3, pp. 130-136, 2012. 
[3] A. Doshi, S. Y. Cheng, and M. M. Trivedi, "A novel active headsup display for driver assistance," IEEE Transactions on Systems, Man, and Cybernetics, Part B: Cybernetics, vol. 39, no. 1, pp. 8593, 2009.

[4] J.-S. Hu, Y.-R. Huang, and F.-R. Hu, "Development of traction control for front-wheel drive in-wheel motor electric vehicles," International Journal of Electric and Hybrid Vehicles, vol. 4, no. 4, pp. 344-358, 2012.

[5] S.-I. Sakai, H. Sado, and Y. Hori, "Motion control in an electric vehicle with four independently driven in-wheel motors," IEEE/ASME Transactions on Mechatronics, vol. 4, no. 1, pp. 9$16,1999$.

[6] J.-S. Hu, D. Yin, and Y. Hori, "Fault-tolerant traction control of electric vehicles," Control Engineering Practice, vol. 19, no. 2, pp. 204-213, 2011.

[7] Y. Hori, "Future vehicle driven by electricity and controlresearch on four-wheel-motored "UOT Electric March II'," IEEE Transactions on Industrial Electronics, vol. 51, no. 5, pp. 954-962, 2004.

[8] J.-S. Hu, D. Yin, Y. Hori, and F.-R. Hu, "Electric vehicle traction control: a new MTTE methodology," IEEE Industry Applications Magazine, vol. 18, no. 2, pp. 23-31, 2012.

[9] G. Zorpette, “The smart hybrid," IEEE Spectrum, vol. 41, no. 1, pp. 36-43, 2004.

[10] S. Li, C. Zhang, and X. Dai, "Design for battery energy manage system based on LabVIEW," in Proceedings of the International Conference on Measuring Technology and Mechatronics Automation (ICMTMA '10), vol. 1, pp. 978-981, March 2010.

[11] H. B. Pacejka and E. Bakker, "The magic formula tyre model," Vehicle System Dynamics, vol. 21, pp. 1-18, 1992.

[12] Y. Hori, Y. Toyoda, and Y. Tsuruoka, "Traction control of electric vehicle: basic experimental results using the test EV UOT electric march," IEEE Transactions on Industry Applications, vol. 34, no. 5, pp. 1131-1138, 1998. 


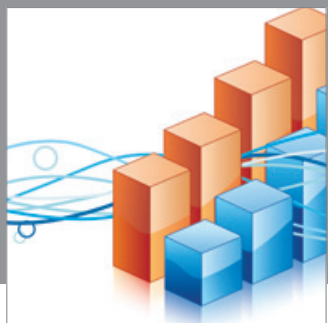

Advances in

Operations Research

mansans

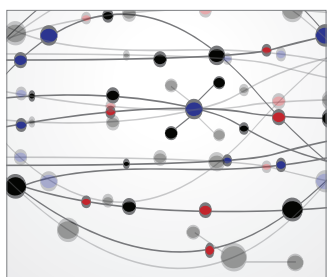

The Scientific World Journal
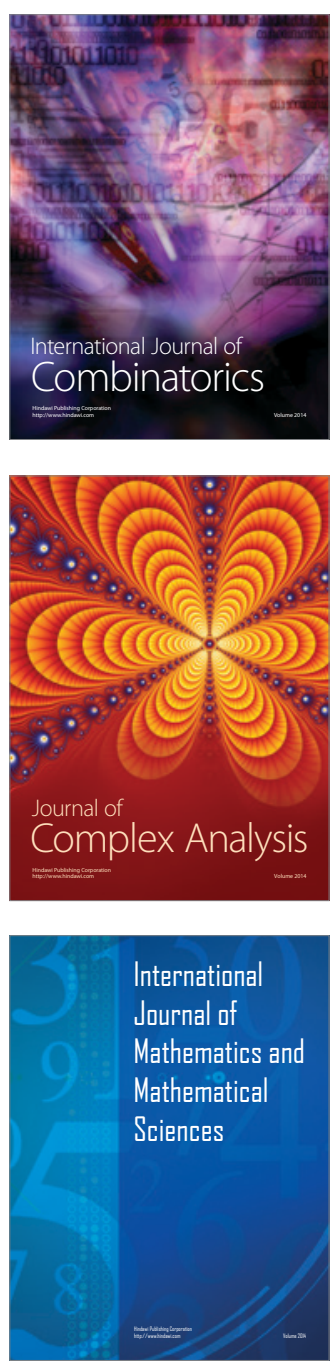
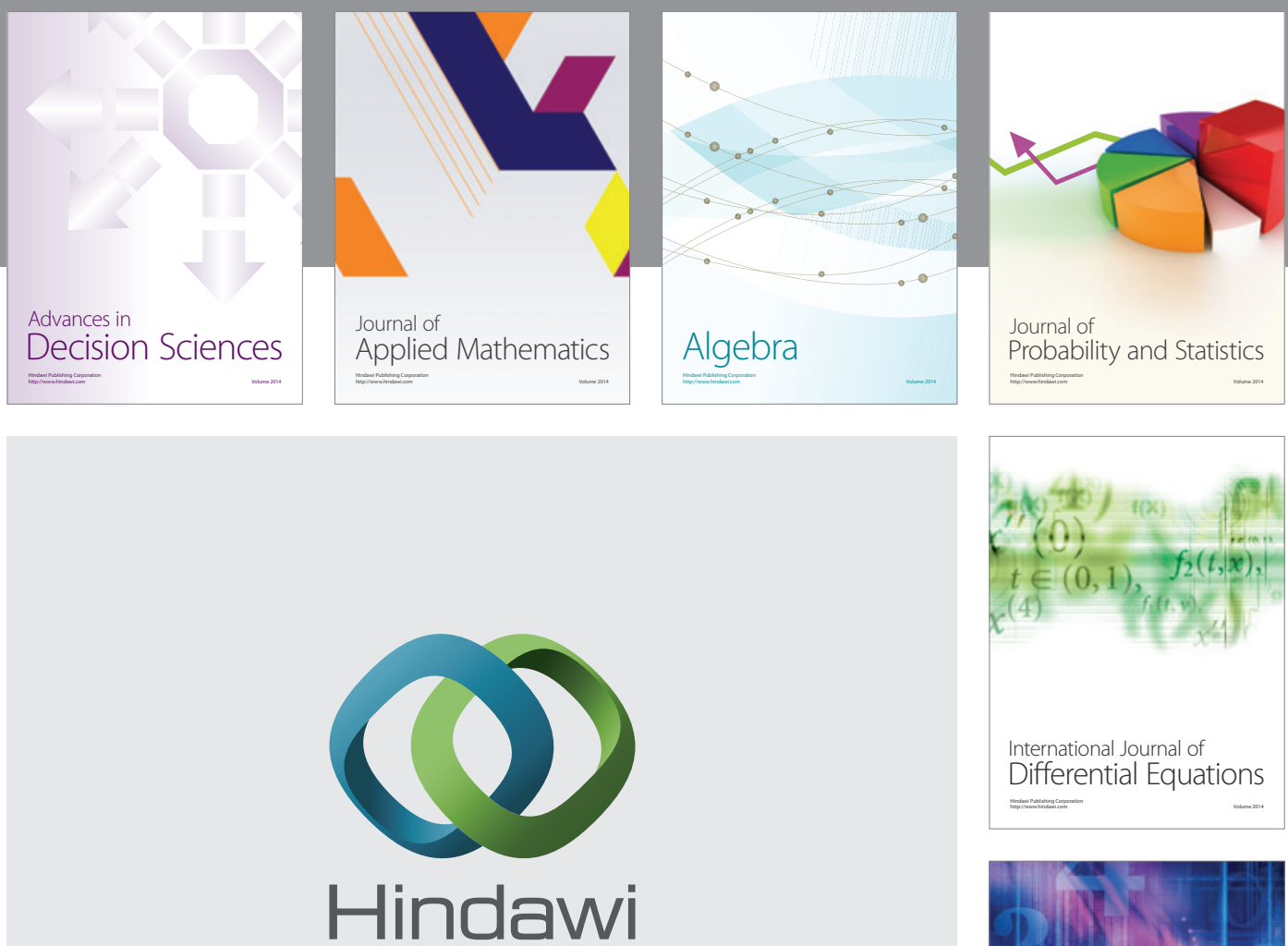

Submit your manuscripts at http://www.hindawi.com
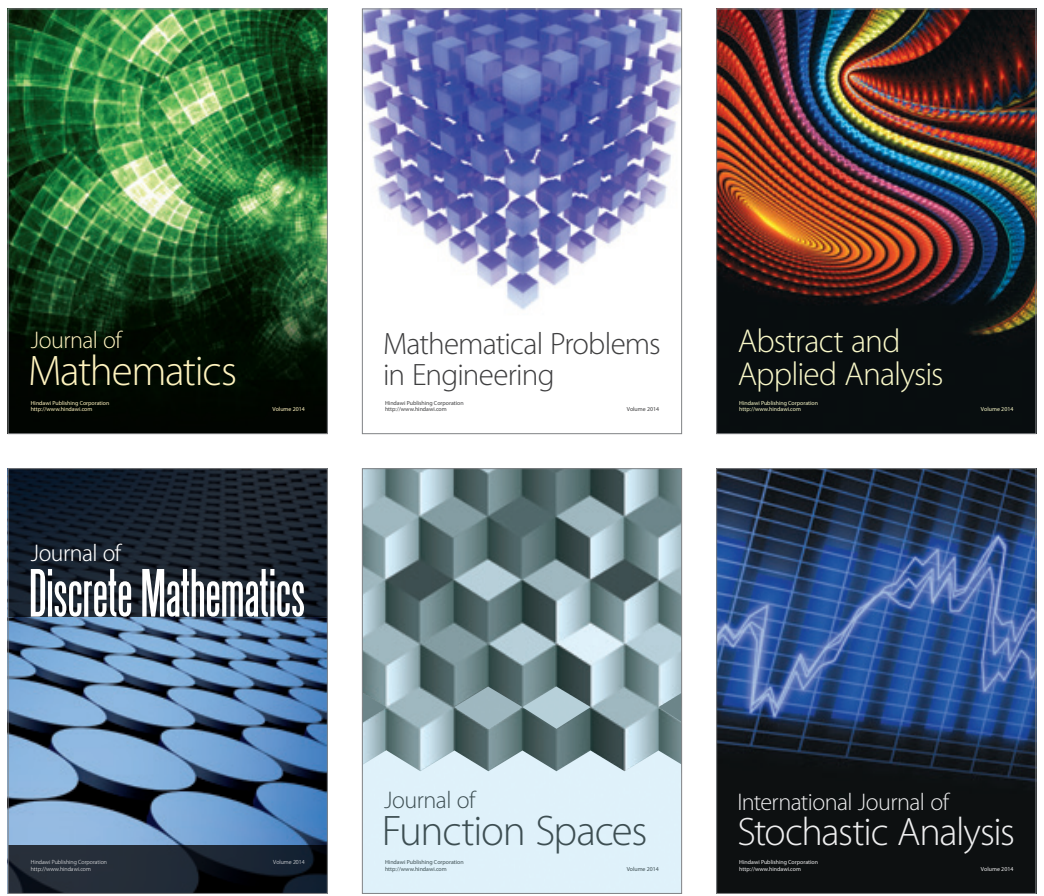

Journal of

Function Spaces

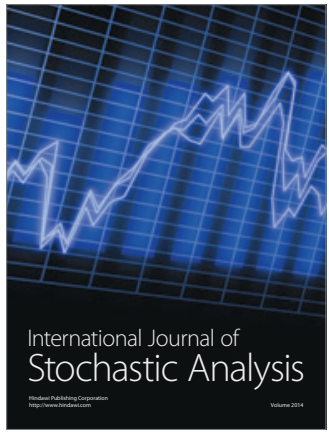

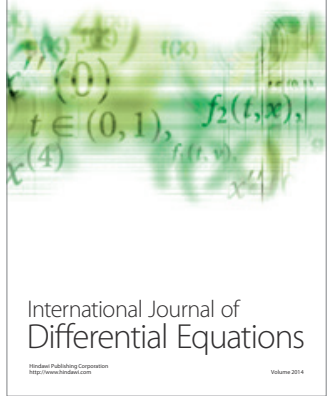
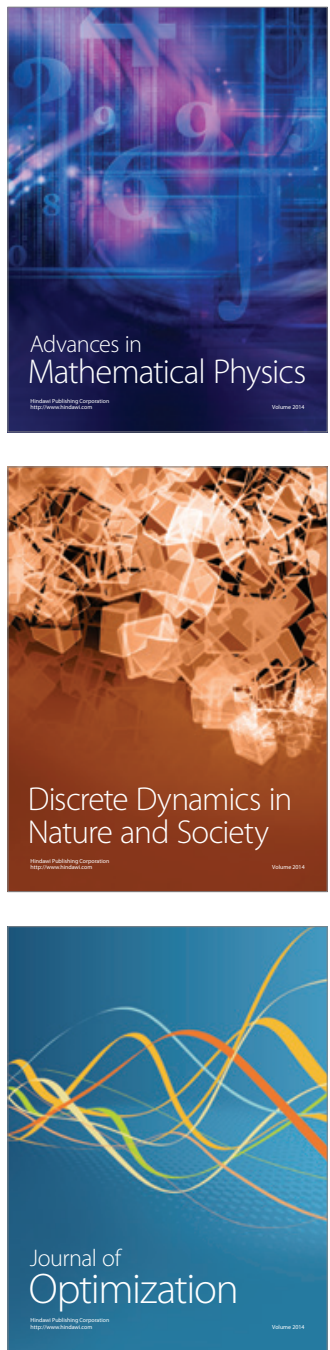